\title{
Grain refinement in an unalloyed tantalum structure by combining Wire + Arc Additive Manufacturing and vertical cold rolling
}

\author{
G. Marinelli*, a, F. Mart naa, S. Gangulya, S. Williamsa \\ aWelding Engineering and Laser Processing Centre (WELPC), College Road, Cranfield \\ University, Cranfield, IMK43 0AL, UK \\ ${ }^{*}$ Corresponding Author. E-mail address: g.marinelli@cranfield.ac.uk (G. Marinelli)
}

\begin{abstract}
Components manufactured via Wire + Arc Additive Manufacturing are usually characterised by large columnar grains. This can be mitigated by introducing in-process cold rolling; in fact, the associated local plastic deformation leads to a reduction of distortion and residual stresses, and to microstructural refinement. In this research, interpass rolling was applied with a load of $50 \mathrm{kN}$ to a tantalum linear structure to assess rolling's effectiveness in changing the grain structure from columnar to equiaxed, as well as in refining the grain size. An average grain size of $650 \mu \mathrm{m}$ has been obtained after five cycles of inter-pass rolling and deposition. When the deformed layer was reheated during the subsequent deposition, recrystallisation occurred, leading to the growth of new strainfree equiaxed grains. The depth of the refined region has been characterised and correlated to the hardness profile developed after rolling. Furthermore, a random texture was formed after rolling, which should contribute to obtaining isotropic mechanical properties. Wire + Arc Additive Manufacture demonstrated the ability to deposit sound refractory metal components and the possibility to improve the microstructure when coupled with cold inter-pass rolling.
\end{abstract}

Keywords: WAAM, Tantalum, Microstructure, Hardness, Cold Working, Additive Manufacturing

\section{Introduction}

One of the most promising manufacturing technologies is Additive Manufacturing (AM) [1,2]. Three-dimensional structures can be promptly deposited starting from 3D-models, using a layer-by-layer approach [3]. The practical advantages are cost reduction, freedom of design and engineered mechanical properties [3]. Numerous studies have already discussed the potential of the AM of metallic materials, some of them are summarised in the work of Frazier [4].

Among the different AM techniques, wire-feed technologies, in particular the Wire + Arc Additive Manufacturing (WAAM) process, which employs an electric arc as the heat source, have already proven capable of producing largescale components [5,6]. WAAM can directly fabricate fully-dense metallic large 3-D near-net-shape components with a higher deposition rate than most other metal 
additive manufacture processes [5,6], the highest reported rate being of $9.5 \mathrm{~kg} / \mathrm{h}$ [7]. The WAAM process has successfully produced large-scale parts in stainless steel [8], Inconel $®$ [9], titanium [10], aluminium [11], tungsten [12,13] and tantalum [14]. Furthermore, functionally graded structures of refractory metals have been deposited using WAAM [15]. The manufacture of large and engineered components by WAAM is attractive also because of the low system and operating costs, as well as the modularity of the system design $[6,16]$.

Tantalum is one of the most promising materials for high-temperature applications due to its high melting point and its inertness at high temperatures [17]. The stable oxide layer that immediately covers tantalum components is the main reason for its chemical stability against corrosion [18]. Furthermore, tantalum is characterised by a large ductility at room temperature, unlike other refractory metals such as tungsten and molybdenum $[19,20]$. These distinctive properties make tantalum a great candidate for the production of components for the aerospace sector as well as the defence, the electronics and chemical industries $[17,19,21]$.

A few studies have been reported with regards to the development of an additive manufacturing process for unalloyed tantalum, mainly employing a laser as the heat source and tantalum powder as the feedstock. Laser-powder-bedfusion (LPBF) has been used by Zhou et al. [22] to produce one of the first additively manufactured structures of unalloyed tantalum. In the work of Thijs et al. [23], the LPBF process was studied for unalloyed tantalum focusing mainly on the microstructural evolution and mechanical properties. Furthermore, tantalum coating has been successfully deposited on titanium using engineered net shaping (LENS) in order to produce controlled porous components with enhanced bioproperties [24]. A further study on porous tantalum parts is reported in the study of Wauthle et al. [25], in which LPBF was used effectively to produce porous tantalum implants with fully-interconnected open pores.

In most industrial sectors where tantalum finds application, a fine equiaxed microstructure with the reduction or elimination of the crystallographic texture is desirable, so as to benefit from improved mechanical properties and complete isotropy. However, most metallic materials, as for instance tantalum, present unique microstructural features such as large columnar grains that can lead to marked anisotropy when processed by AM $[3,23,26]$. Microstructural refinement in AM structures can be achieved in various ways. In spite of this, methods such as the optimisation of process parameters to change the solidification regime, or the alteration of alloy chemistry [27], are not suitable when the stability of the process must be controlled constantly, and the purity of the alloys used must be preserved. A viable option could be based on inducing plastic deformation within the deposited layer and subsequent deposition of a new layer (effectively equal to a local heat treatment) [26]. This has been already proven for Ti-6Al-4V, where the 
columnar prior- $\beta$-grains and the strong fibre texture have been completely eliminated [26].

For tantalum components, investigations regarding the effect of rolling, high-pressure torsion and equal-channel angular pressing on the microstructural refinement have already been reported [28-32]. In particular, ultrafine and nanostructured tantalum components can be produced by applying severe plastic deformation steps to a conventional coarse-grained structure, achieving nanometre-size grains [30,33]. Such fine microstructure is desirable; for instance, if tantalum is used as a sputtering target because a strong texture would lead to an inconsistent erosion rate through the surface of the target $[34,35]$.

In general, unalloyed polycrystalline tantalum is characterised by a recrystallisation temperature that varies within the range from $900^{\circ} \mathrm{C}$ to $1450^{\circ} \mathrm{C}$, depending on the level of impurities and, predominantly, on the level of strain/deformation [28]. Usually, a high content of impurities increases the recrystallisation temperature. Köck et al. [17] reported that the deformation of arcmelted tantalum components can be pronouncedly influenced by metalloids such as carbon, nitrogen and oxygen. In the work of Mathaudhu et al. [36], the reported recrystallization curves showed that all tantalum specimens were fullyrecrystallized at $1100^{\circ} \mathrm{C}$, but some of the samples recrystallised between $900^{\circ} \mathrm{C}$ and $1000^{\circ} \mathrm{C}$, depending on the degree of deformation applied. A typical range of strain level in unalloyed tantalum, in order to obtain recrystallisation, was indicated to range from 1.2 to 4.6 [37]. The recrystallisation temperature associated to different strain levels was also indicated: samples with a strain of 1.2 recrystallised at $1100^{\circ} \mathrm{C}$; those with a strain of 2.32 recrystallised at $1000^{\circ} \mathrm{C}$; and those with a strain of 3.48 recrystallised at $900^{\circ} \mathrm{C}$ [37].

In this paper, the potential for microstructure refinement in tantalum by the addition of cold-work has been investigated. In particular, the aim of the study was to verify whether sufficient plastic strain could be introduced by inter-pass rolling and whether recrystallisation would occur during the subsequent deposition. The impact of the rolling load on the depth of refining and grain size has been evaluated and correlated with different hardness profiles measured in the structures. The influence of the recrystallisation on the developed crystallographic texture was also characterised.

\section{Material and Methods}

Unalloyed tantalum wire with a diameter of $1.2 \mathrm{~mm}$ was used for the Wire + Arc Additive Manufacturing process. A cold-rolled tantalum plate with a length of $210 \mathrm{~mm}$, a width of $50 \mathrm{~mm}$ and a thickness $4 \mathrm{~mm}$ was used as substrate to start the deposition. The surface of the plate was ground and rinsed with acetone prior to 
the deposition to remove most of the contaminants. The composition of the material used is shown in Table 1.

Table 1

Elemental composition (wt.\%) of the tantalum substrate and wire used in this study.

\begin{tabular}{|c|c|c|c|c|c|c|c|c|c|c|c|}
\hline & $\mathbf{W}$ & Mo & $\mathbf{T a}$ & $\mathbf{T i}$ & V & $\mathrm{Cr}$ & $\mathbf{F e}$ & C & $\mathbf{N}$ & $\mathbf{0}$ & $\mathbf{K}$ \\
\hline Substrate & $<0.05$ & $<0.05$ & 99.99 & $<0.05$ & $<0.05$ & $<0.05$ & $<0.05$ & $\begin{array}{l}33 \\
\text { ppm }\end{array}$ & $\begin{array}{l}<10 \\
\text { ppm }\end{array}$ & $\begin{array}{l}60 \\
\text { ppm }\end{array}$ & $\begin{array}{l}<10 \\
\text { ppm }\end{array}$ \\
\hline Wire & $<0.05$ & $<0.05$ & 99.98 & $<0.05$ & $<0.05$ & $<0.05$ & $<0.05$ & $\begin{array}{l}36 \\
\mathrm{ppm}\end{array}$ & $\begin{array}{l}11 \\
\mathrm{ppm}\end{array}$ & $\begin{array}{l}190 \\
\text { ppm }\end{array}$ & $\begin{array}{l}<10 \\
\mathrm{ppm}\end{array}$ \\
\hline
\end{tabular}

Fig. 1 shows the layout of the apparatus used for the deposition. The cartesian reference system used throughout the experiment is reported for all the schematics. A conventional tungsten inert gas (TIG) welding torch, a power supply and a controlled wire feeder were used for the deposition. The heat source, the wire delivery system and the substrate were attached to three linear motorized high-load stages assembled in XYZ configuration.

The direction of deposition was always kept constant for each successive layer and the wire was fed from the side of the weld pool. The apparatus was surrounded by a heavy-duty enclosure, purged with high-purity argon to keep the level of $\mathrm{O}_{2}$ around $100 \mathrm{ppm}$. The linear structure was produced using the parameters shown in Table 2. Please note the choice of $100 \%$ He as process gas for TIG, following from what concluded in our previous study [38]. A straight wall was produced with a length of $190 \mathrm{~mm}$. All the samples analysed within this study were extracted from the same build.

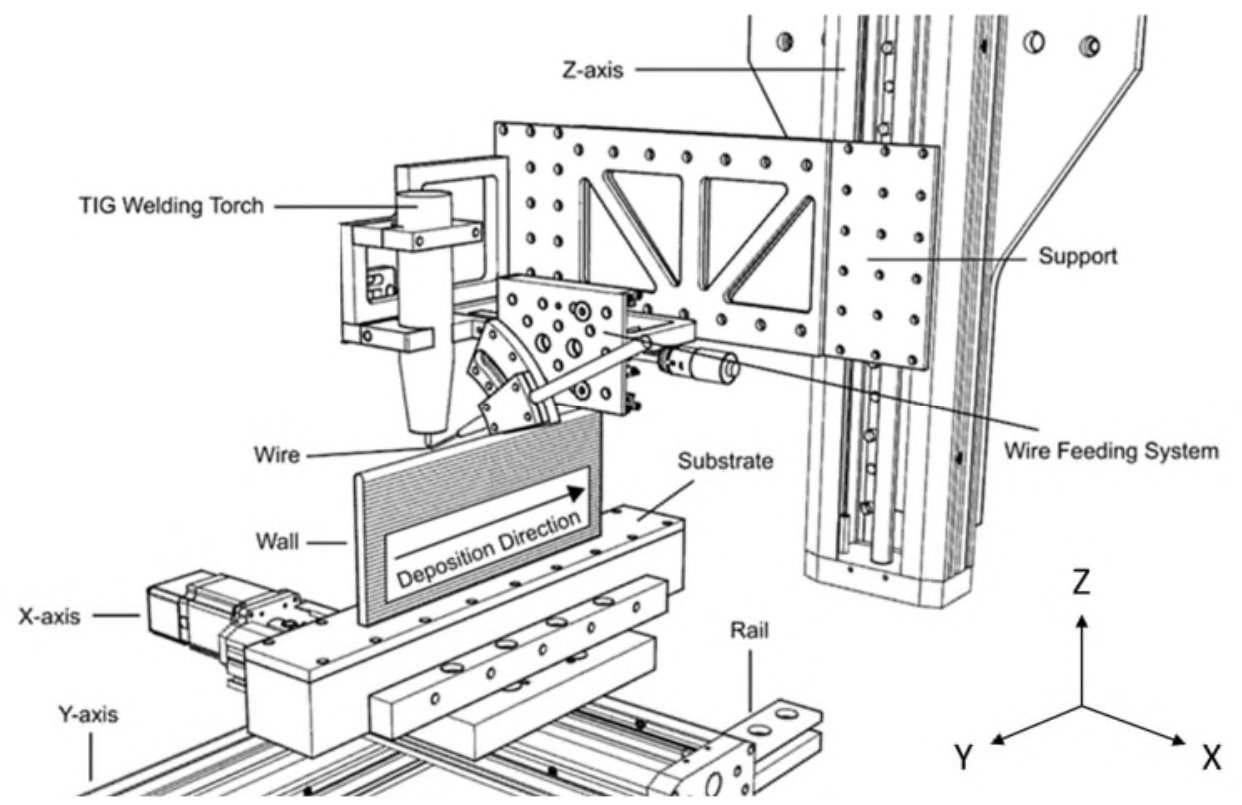

Fig. 1: Set-up used for the deposition of unalloyed tantalum using the WAAM process. 
Table 2

WAAM process parameters used for the deposition of unalloyed tantalum.

\begin{tabular}{ll}
\hline Parameter & Value \\
\hline Travel Speed (TS) [mm/s] & 4 \\
Welding Current (I) [A] & 300 \\
Wire Feed Speed (WFS) [mm/s] & 40 \\
TIG process gas [\%] & $100 \mathrm{He}$ \\
Gas Flow Rate (GFR) [L/min] & 15 \\
Oxygen Level [ppm] & $\approx 100$ \\
\hline
\end{tabular}

A rolling rig was used for the application of inter-layer cold working. The roller travelled at a constant speed of $10 \mathrm{~mm} / \mathrm{s}$, applying a vertical load of $50 \mathrm{kN}$ onto the structure deposited. A schematic diagram of the rolling equipment is shown in Fig. 2. The force applied by the roller was calibrated with a load cell before the experiments. Every rolling pass was carried out when the material had cooled down to room temperature.

Please note that the specimen had to be taken out of the inert environment whilst still clamped to the backing bar, placed on the rolling rig for the rolling pass, and then returned to the enclosure for where the inert environment had to be recreated for the following layer deposition, which started only after the oxygen content was below $100 \mathrm{ppm}$. Rolling and deposition had to be done on two different set-ups because creating an inert atmosphere around the entire rolling rig was not practical.

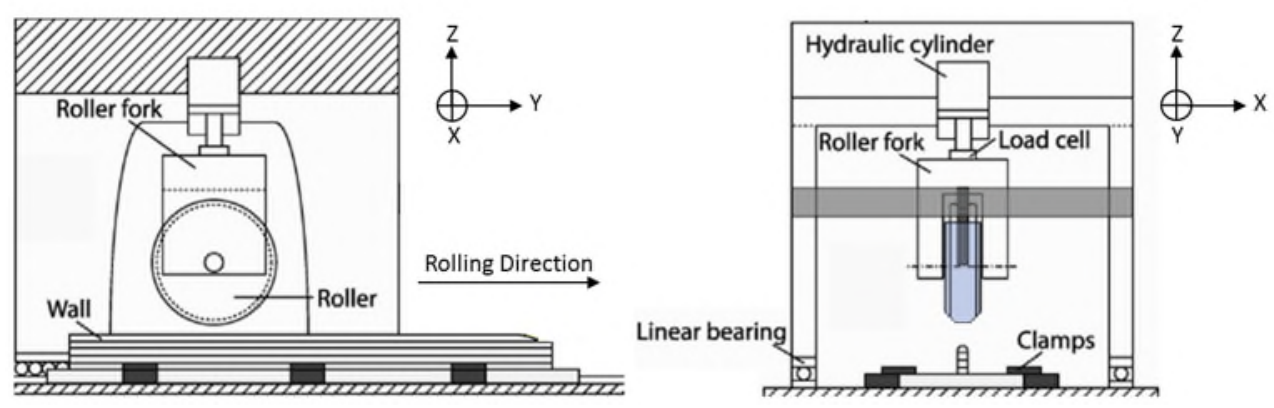

Fig. 2: Schematic of the rolling rig used for the application of cold working between each successive layer.

The location and the manufacturing route for each sample analysed are shown in Fig. 3. Four main samples were produced using a different combination of deposition and rolling. The sample called $1 \mathrm{R}$ was manufactured only after the deposition of 15 layers of unalloyed tantalum without the application of any rolling steps and served as control specimen. The sample 2R was extracted from the portion of the wall that was normally deposited for 15 layers and rolled once, at the top. The sample 3R had the same history of $2 \mathrm{R}$, except a 16th layer was deposited on top of the rolled one. The sample 4R had 15 layers of the deposition 
without any rolling, after which 5 more layers were deposited with inter-pass rolling applied. The regions from which sample $1 \mathrm{R}$, sample $2 \mathrm{R}$ and sample $3 \mathrm{R}$ were extracted were $40 \mathrm{~mm}$ long and the sample $4 \mathrm{R}$ was extracted from the remaining 70-mm-long structure. The structure was produced gradually decreasing the deposition and the rolling path length.

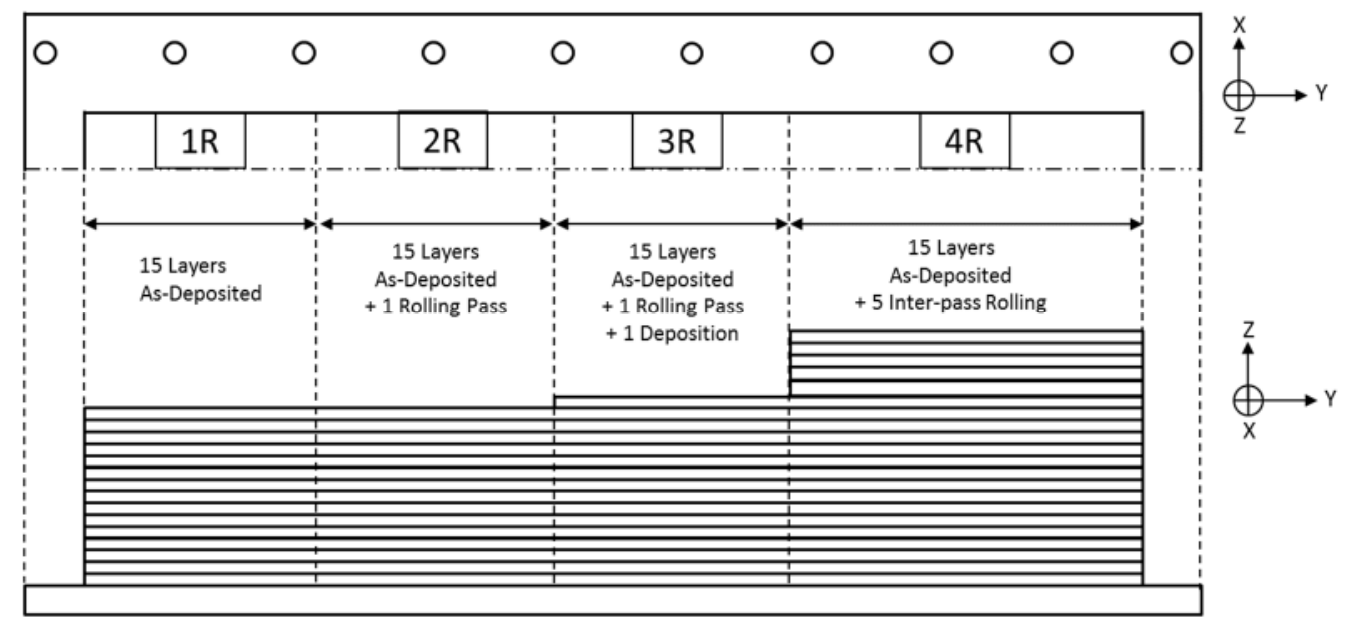

Fig. 3: Schematic of the manufacturing route used to produce each sample analysed. The name of the samples extracted per each region is also reported.

The samples were ground, polished and etched, and analysed for hardness, grain size and texture. The microstructure was examined using the cross-section perpendicular to the deposition direction. Vickers hardness contour maps were produced using the measurements collected using an automatic hardness testing machine. The main parameters for the hardness acquisition were $500 \mathrm{~g}$ load and 10 seconds dwell time for each testing point. Several line-scans with $1 \mathrm{~mm}$ spacing were performed throughout the height and width of each cross-section to obtain the contour maps of hardness. The microstructure of the sample 4R was characterised by scanning electron microscope (SEM) operating at $20 \mathrm{kV}$. Grain size and grain orientation were measured with the aid of an electron backscatter diffraction (EBSD) detector within the SEM. Pole figures and inverse pole figures were used to evaluate the texture. The sample $4 \mathrm{R}$ was chosen as it was the sample that showed the most evident contrast in microstructure within the same build. The root and the top of the samples were measured to understand the variations within the microstructure. 


\section{Results}

\subsection{Microstructure}

a)

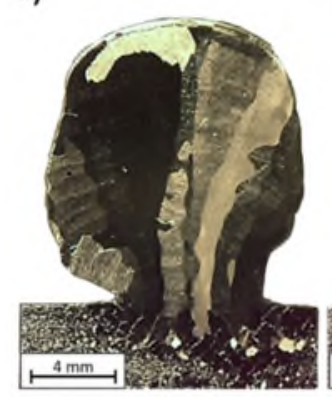

b)

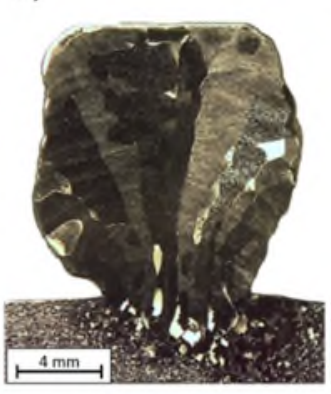

c)

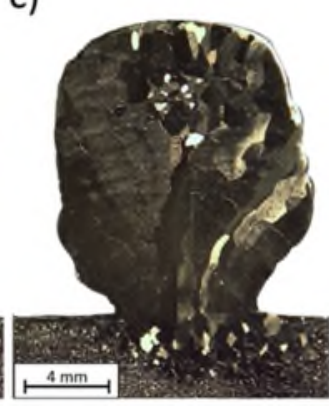

d)

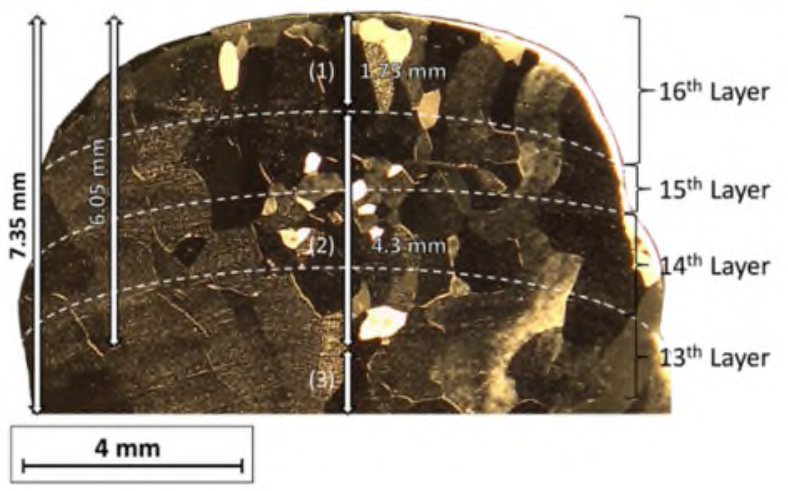

Fig. 4: Optical micrographs of sample 1R (a), 2R (b) and 3R (c). High magnification of the recrystallised top part of sample $3 \mathrm{R}(\mathrm{d})$.

The microstructure of 1R, 2R and 3R are reported in Fig. 4a, Fig. $4 \mathbf{b}$ and Fig. 4c respectively. All the samples produced presented a smaller width near the baseplate due to a change in thermal flow characteristic of the deposition process, which has been explained elsewhere [39]. The sample 1R (Fig. 4a) demonstrated large columnar grains, which grew epitaxially from the base plate toward the top of the sample parallel to the building direction, with columnar grains that were 1$\mathrm{mm}$-wide on average and extended from the base plate to the top of the deposit. For $2 \mathrm{R}$, the size and the morphology of the grains were essentially the same as $1 \mathrm{R}$ as the only rolling pass just flattened the upper surface, plastically deforming the structure (Fig. 4b). The sample 3R (Fig. 4c) presented a significant reduction in grain size and a change in morphology for the grains localised in the upper region. The majority of the refined equiaxed grains had a size between $250 \mu \mathrm{m}$ and 350 $\mu \mathrm{m}$. There were a few larger grains which had a size between $600 \mu \mathrm{m}$ and $850 \mu \mathrm{m}$.

Fig. 4d shows a higher magnification micrograph of the refined region of sample 3R. The lines identifying the individual layers could be traced thanks to the geometrical features of the outer surfaces. The last four layers were chosen to illustrate the depth and width of the refined region. In particular, the top $7.35 \mathrm{~mm}$ 
of the structure are reported, and three different zones of the microstructure can be distinguished: the last deposited layer (1) which is effectively in the asdeposited conditions, with finer columnar grains growing epitaxially from the refined grains below; the refined region (2) which extended from $1.75 \mathrm{~mm}$ in depth until $6.05 \mathrm{~mm}$ in depth, across three layers below the last one (from the fifteenth to the thirteenth layer) and was localised at the middle of the structure; and the layers (3) where the effect of rolling was not visible and where the large columnar grains were left unchanged.

In Fig. 5a and Fig. 5b is shown an unusual banding seen across some grain boundaries in sample 2R. Each line of the bands was pointing in the direction of around $30^{\circ}$ to $45^{\circ}$ compared to the Z-axis. These deformation bands were associated with a high degree of deformation induced by the rolling.
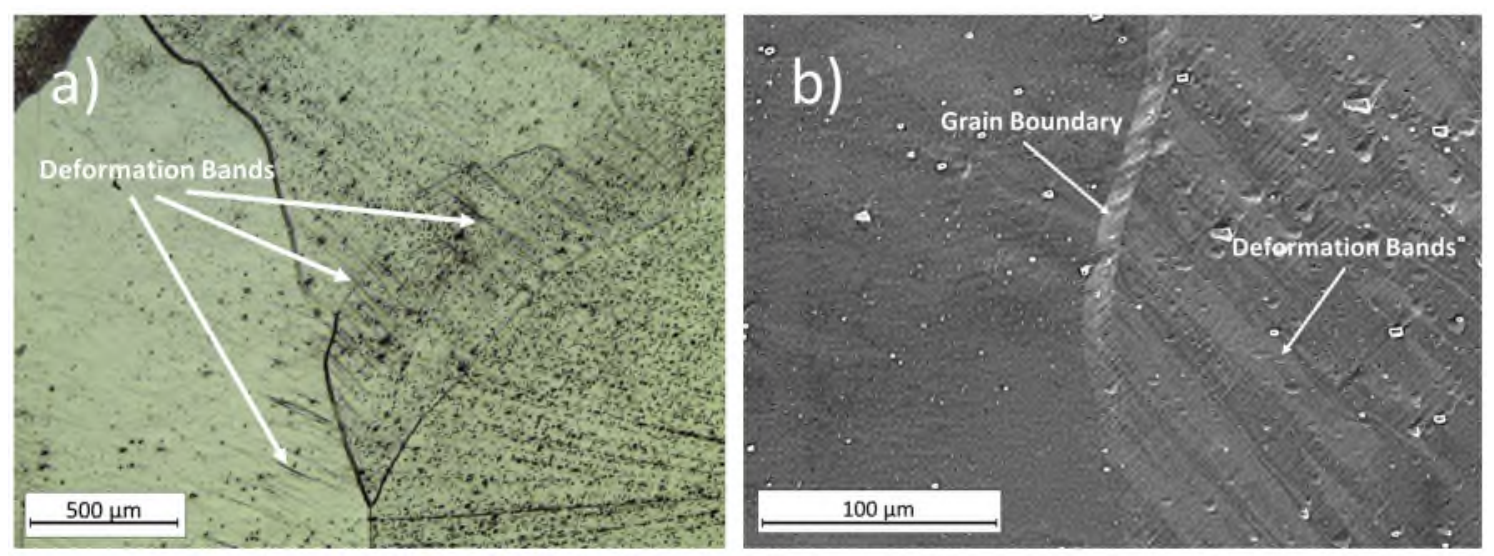

Fig. 5: Optical microscope (a) and SEM (b) picture of deformation bands in sample 2R.

The microstructural features of the sample 4R are reported in Fig. 6. In particular, Fig. 6a shows the entire cross-section, with a marked change in microstructure for the upper layers. The boundaries of each layer were not clear due to the considerable lateral and vertical deformation given by inter-pass rolling. The large columnar grains typical of the as-deposited condition extended from the substrate until $7.25 \mathrm{~mm}$ in height.

The refined region extended for around $6.4 \mathrm{~mm}$ in height and it had a total width of around $7.6 \mathrm{~mm}$. Average grain size was around $650 \mu \mathrm{m}$. The top $2.2 \mathrm{~mm}$ presented a typical microstructure of the as-deposited layer without any rolling after deposition, similar to the top of sample 3R. Fig. 6b report details of the microstructure of the refined with highlighted grain boundaries. 
a)

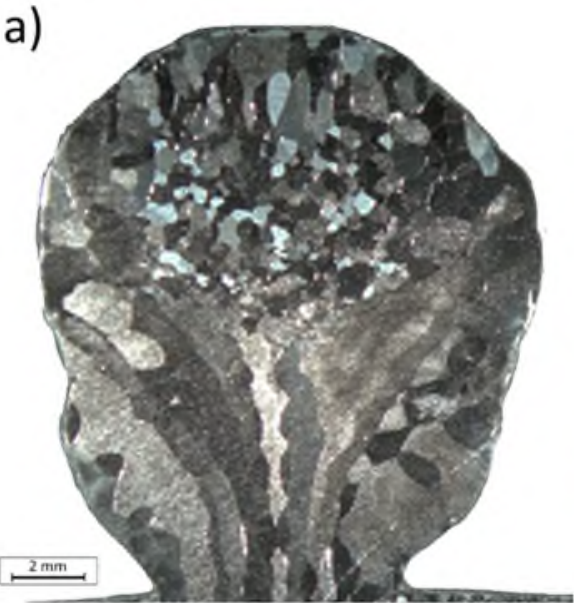

b)

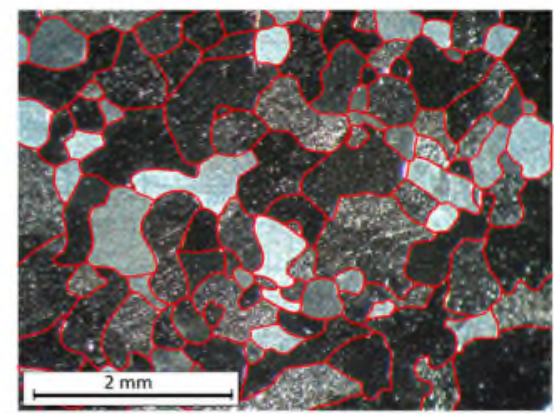

Fig. 6: Optical micrograph of sample 4R (a). Detail of the microstructure from the recrystallised zone (b) with highlighted grain boundaries.

\subsection{Hardness}

As the application of strain gauges on the external surfaces of the wall was not possible due to the surface roughness and the extremely high temperature given by the deposition, the hardness profile was used to evaluate the strain distribution within the bulk of the structure. This because it is well known that tantalum components are subjected to considerable strain hardening, when cold working is applied, due to a high dislocations density produced by the plastic deformation $[37,40]$. Thus, the change in hardness after rolling can be directly associated with the strain.

Fig. 7a reports the hardness distribution for the sample $1 \mathrm{R}$, which represents the as-deposited material (control). The hardness was consistent, with small fluctuations around a mean value of $114 \mathrm{HV}$ across the width and height. Fig. $\mathbf{7 b}$ reports the hardness map for the sample $2 \mathrm{R}$, after the single rolling pass. The impact of rolling on the hardness values and distribution can be seen clearly. The application of rolling increased the hardness of the whole structure down to 10 $\mathrm{mm}$ from the top. A predominant high-hardness region developed from $1.0 \mathrm{~mm}$ to $6.5 \mathrm{~mm}$ in depth, with a width of around $4.0 \mathrm{~mm}$. The hardness almost doubled reaching the value of $205 \mathrm{HV}$ at its peak. Fig. 7c shows the hardness distribution of the sample 3R. The overall hardness of the structure was reduced compared to the rolled structure. From the top, down to a depth of $1.75 \mathrm{~mm}$, the hardness reduced and was similar to the average hardness of $1 \mathrm{R}$, the as-deposited material. This means that the deposition of a new layer effectively annealed the underlying material. 

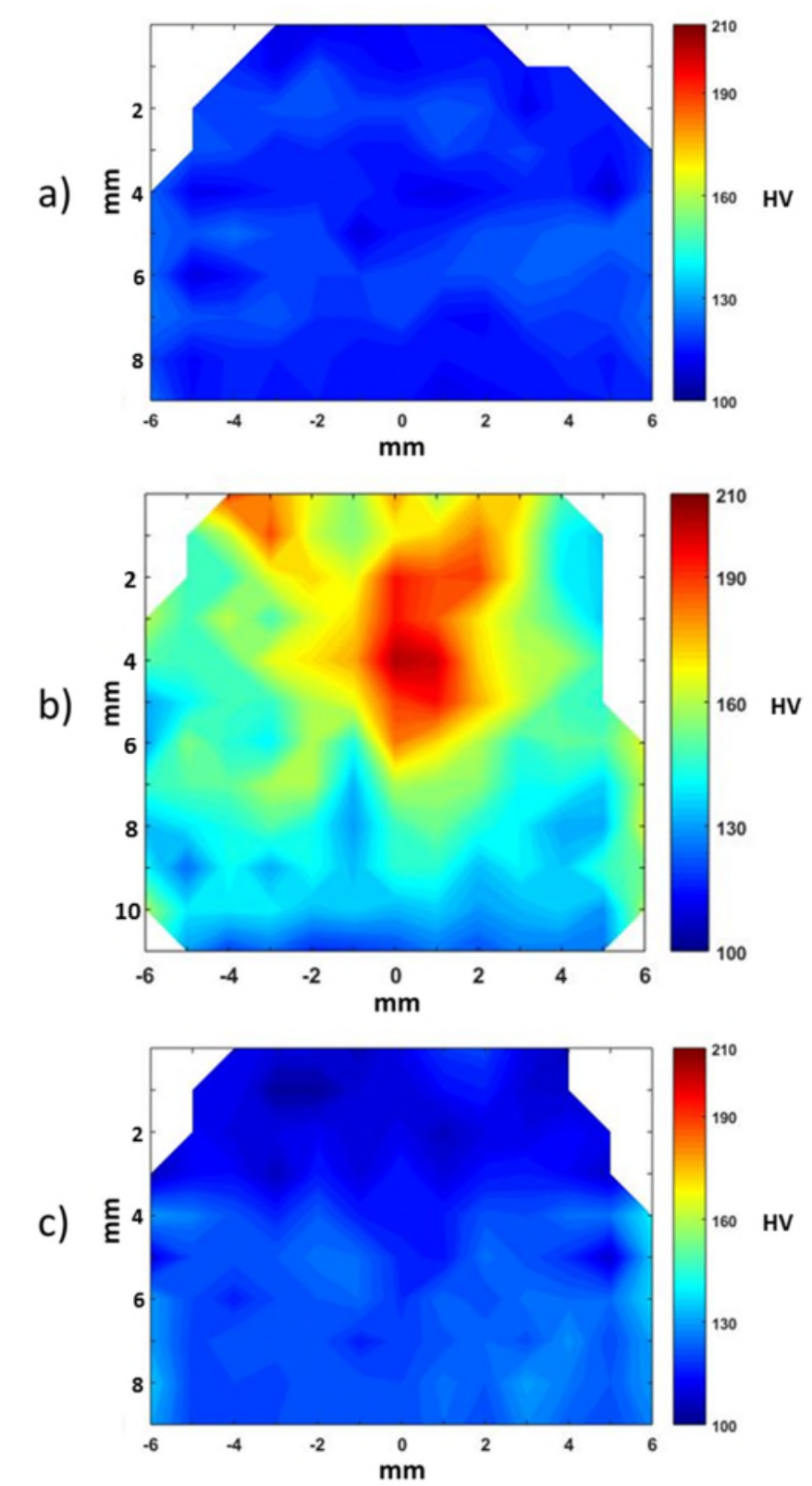

Fig. 7: Contour maps relative to the Vickers hardness measurements for sample 1R (a), 2R

(b) and 3R (c).

In the work of Aditya et al. [29] on cold rolling of tantalum sheets, a trend between cold reduction (strain) and Vickers hardness was clearly shown. An increment in average hardness was seen until cold reduction superior to $65 \%$, where the hardness stabilised around $200 \mathrm{HV}$. In the work of Mathaudhu et al. [36], the hardness of an arc-melted tantalum ingot was reported to increase after rolling. In particular, a hardness of $170 \mathrm{HV}$ was reached after one rolling cycle and a hardness of $210 \mathrm{HV}$ after two rolling cycles. In other studies on rolling of tantalum plates, micro-hardness values reached maximum levels around $230 \mathrm{HV}$ after only two rolling cycles with a strain of 2.3 [32]. In general, a plateau of hardness was always seen around $210 \mathrm{HV}-220 \mathrm{HV}$ for the studies available in the 
literature, even for a high level of deformation. This saturation in formability and hardness is associated with the high density of dislocations, which obstacle their own further motion [29].

An empirical relation has been proposed in the literature [41] which correlated dislocation density $(\rho)$ to the variation of Vickers hardness for cold worked tantalum. The equation is reported as following (Eq. 1):

$\rho=1.6 \times 10^{9}\left(m^{-2}\right)\left(\frac{H-H_{\text {ing }}}{M P a}\right)^{2}$

Where $\mathrm{H}$ is the Vickers hardness after cold working and $\mathrm{H}_{\text {ing }}$ is the hardness of the as-received material prior to deformation. Stuwe et al. [41] also proposed a minimum critical dislocation density in order to have spontaneous nucleation, which was indicated to be equal to $3 \times 10^{14} \mathrm{~m}^{-2}$. From the equation reported, the corresponding Vickers hardness to the critical dislocation density is equal to 130 $\mathrm{Hv}[29,41]$.

When considering the hardness distributions reported in Fig. 7, it is possible to assess that the rolling step clearly induced a certain amount of strain within the bulk material associated with an increase in hardness to values as high as $210 \mathrm{HV}$. The deformation localised around the hardness maximum should also be considered characterised by a considerably high dislocation density, enough to induce recrystallisation.

The contour map of sample 3R (Fig. 7c) shows how the thermal field developed after the deposition affected the hardness of the entire structure. There were particularly three main regions characterised by the hardness and the location. These regions corresponded precisely with the three regions of microstructure reported in sample 3R (Fig. 4d).

The upper region extended from the top of the sample until $1.75 \mathrm{~mm}$ in depth, which corresponded precisely to the fusion boundary location of the last layer (Fig. 4d). Here, the hardness was found to be very close to the as-deposited material.

The region below this one corresponded entirely to the recrystallised region. The hardness was correlated to the size and shape of the new recrystallised grains. Even if the strain was almost totally relieved by the formation of the new defect-free grains, the density of grain boundaries locally increased when compared to the parent columnar grains. The grain boundaries impeded the dislocation movements. This has led to a local strengthening effect according to the Hall-Petch relation.

Moreover, the lower part of the sample 3R was characterised by a general decreasing in hardness when compared with the same area of sample $2 \mathrm{R}$ but showing same retention of strain. At this depth, the change in strain concentration and the dislocation density induced by the rolling was not sufficiently high to induce recrystallisation so that recovery occurred. Thus, the small driving force, in 
terms of strain and temperature, led to a general softening without the formation of new grains.

The critical hardness value of $130 \mathrm{HV}$ obtained by the relation indicated by Stuwe et al. (Eq. 1) has been achieved for the top $8.0 \mathrm{~mm}$ of the sample 2R. Despite the dislocation density of $3 \times 10^{14} \mathrm{~m}^{-2}$ associated with this hardness value and the assertion that this is the minimum value to obtain nucleation of new grains, the recrystallization occurred only within a region characterised by a hardness ranging between $170 \mathrm{HV}$ to $205 \mathrm{HV}$. The dislocation densities associated with these values of hardness should be respectively $5 \times 10^{14} \mathrm{~m}^{-2}$ and $1.2 \times 10^{15} \mathrm{~m}^{-2}$ using the relation of Stuwe et al. (Eq. 1).

This equation does not consider the effect of interstitials on the hardness in tantalum. In fact, it is known that nitrogen and oxygen are strong hardeners of unalloyed polycrystalline tantalum [42]. In the work of Stecura [43], it is shown that the hardness of tantalum increased almost linearly when increasing oxygen content in solid solution. In this study, the hardness of $114 \mathrm{HV}$ for the as-deposited differs from the typical hardness of a tantalum structure, which results to be equal to $90 \mathrm{HV}$, mainly due to the $226 \mathrm{ppm}$ of oxygen within the wire (Table 1). The small amount of oxygen within the material used led to a more pronounced strain hardening so that a higher nominal value of hardness was measured after cold working. Hence, the dislocation density for each region of sample $2 \mathrm{R}$ should be considered slightly lower than the over-estimation from the Eq. 1.

\subsection{Texture}

The images reported in Fig. 8 are maps acquired at the columnar and refined regions of sample 4R. The orientation of the crystals is indicated in the direction parallel to the building direction (Z-axis). The columnar region (Fig. 8a) was characterised by the absence of columnar grains oriented in the $<101>$ direction, showing some preferential directions of crystallisation. The EBSD map for the refined region (Fig. 8b) presents much more refined grains with random orientation. Here, the columnar grains were completely refined to equiaxed grains, and the preferred orientation of crystals developed during deposition was eliminated. 


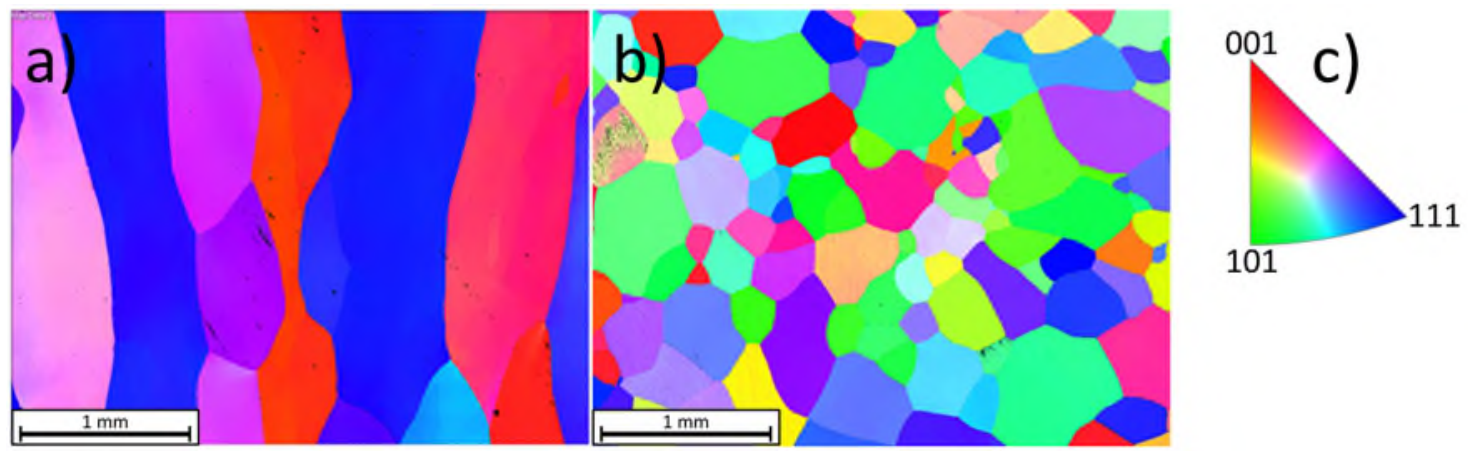

Fig. 8: EBSD images of the columnar as-deposited region (a) and the recrystallised grains (b) of sample 4R. Legend with regards to colour and orientation (c).

a)
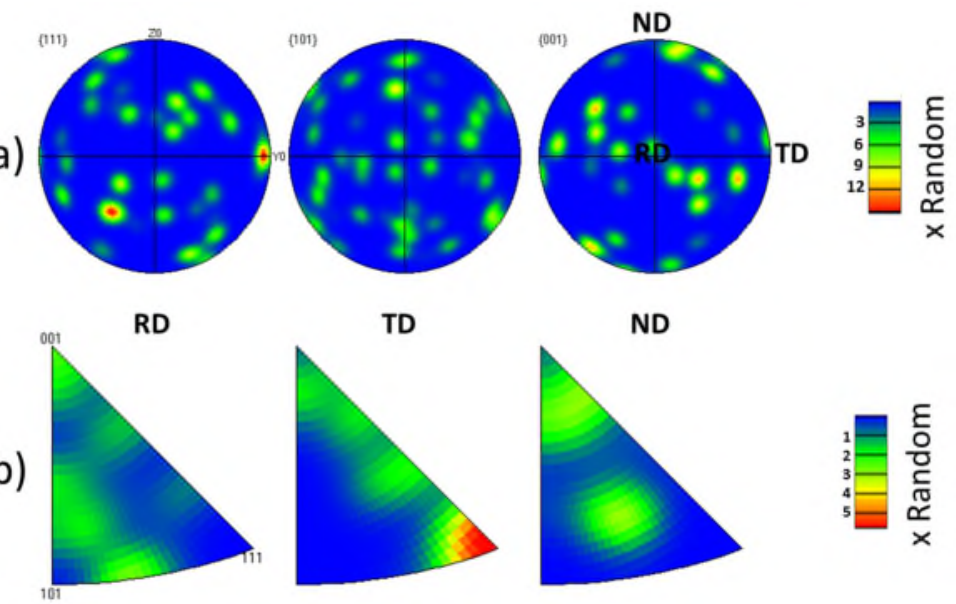

TD

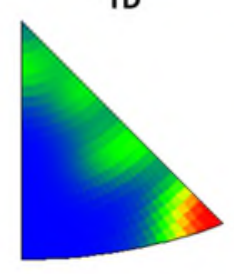

ND
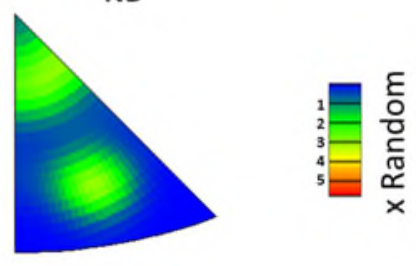

c)

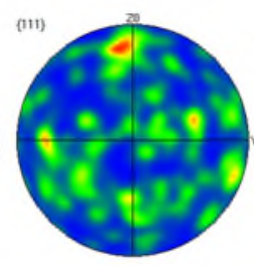

RD

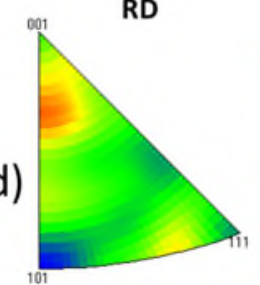

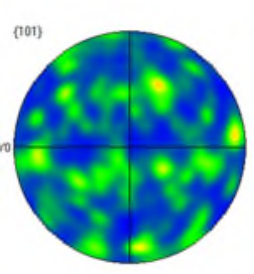

TD

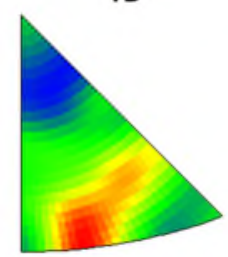

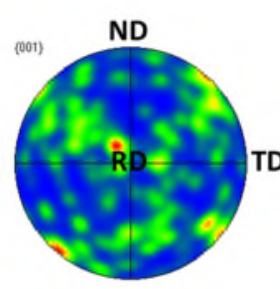

ND

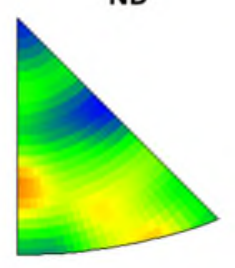

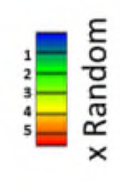

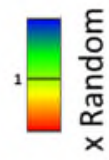

Fig. 9: Pole figures and inverse pole figures obtained from EBSD maps for the columnar asdeposited region (a-b) and the recrystallised grains (c-d) of sample 4R, where ND is parallel to the build direction.

When comparing Fig. 9a and Fig. 9c, the change in texture due to rolling is evident. Note that ND is parallel to the build direction. The columnar as-deposited region showed pole intensities peaking at $12 \mathrm{x}$ random, while for finer equiaxed grains the peak intensities were around $5 \mathrm{x}$ random. A marked scatter of the signal from different crystallographic planes was also clear for the refined region. It is 
important to note that the columnar grains were not characterised by a strong texture but showed a preferred orientation in the $<111>$ direction (Fig. 9b).

In the current study, the rolling load was applied in the direction parallel to the major axis of the columnar grains of the tantalum structure. Under this compressive stress, the columnar grains were deformed not only in the vertical direction but also laterally. This led to the formation of deformation bands among multiple grains with an angle close to $45^{\circ}$ compared to the direction of the load applied (Fig. 5).

Similar features have been seen from Mathaudhu et al. [32] and they have been addressed to the occurrence of slip. Nemat-Nasser et al. [44] affirmed that the slip of the screw dislocations on $\{110\}$ planes was the dominant deformation mechanism observed in tantalum. Furthermore, elongated dislocations cells with small misorientations were found to form bands which were defined as the predominant microstructural characteristic of the shear-localization region. Microbands have also been reported in tantalum and their existence was mainly associated with the primary slip system in a $<111>$ crystal direction [45].

In the study of Liu et al. [45], it has been seen that grains in $<111>$ direction stored a higher amount of energy compared to the other directions and also $<111>$ grains were the preferential place for nucleation of recrystallised grains after application of thermal energy.

Although this value should be treated with caution as the mapped area was relatively small and the grain size was large, the as-deposited columnar grains shown in this work presented some preferred orientation in the direction $<111>$ (Fig. 8a, Fig. 9a-c). The deformation applied by the roller led to the development of deformation bands, potentially series of slips, which have acted as nucleation sites for recrystallisation. The investigation needs further analysis in order to understand which family of crystal imperfections actually acted as a nucleation site for the new strain-free grains. The main factor influencing the grains texture developed from recrystallisation is definitely the nucleation mechanism. The shear bands found within and across the columnar grains after rolling represent a strong conglomeration of crystals defects which could act as nucleation sites. Nucleation of strain-free grains at shear bands has been observed in many metals including copper and its alloys [46,47] and aluminium [48]. In this study, the new recrystallised grains have a completely different orientation when compared to the deformed parent metal. The orientation of recrystallization may correspond to the randomly orientated defects/nuclei placed within the slip bands. 


\section{Conclusions}

The impact of cold vertical rolling with a load of $50 \mathrm{kN}$ on the microstructure and the texture of an AM tantalum component has been studied. A fundamental study has been performed in order to understand the change in microstructure and hardness that occurred after every step of the process. Three main samples corresponding to three sequential steps were used in this study: the as-deposited material (sample 1R), as-deposited + rolling (sample 2R), asdeposited + rolling + deposition (sample 3R). In the samples studied, the rolling load applied caused a compressive strain within the previously-deposited layers and the thermal field of the subsequent deposition allowed new recrystallised grains to form and grow. The recrystallisation occurred within the centre of the deposited structure, where the peak of strain was located and was extended as deep as three layers below the last deposited one. Successive steps of rolling and deposition led to a progressively larger area of equiaxed grains with an average grain size of $650 \mu \mathrm{m}$ after five inter-pass rolling steps. The main findings of the study are summarised as follows:

- By combining the effect of cold rolling and the successive layer deposition, it is possible to achieve recrystallisation in AM tantalum components;

- The refined region found in sample 3R exactly corresponded to the peak in hardness of sample 2R. Thus, the evaluation of strain distribution using hardness map helped to understand the depth of the deposit affected the single rolling step;

- The new strain-free grains presented an equiaxed microstructure and a complete random texture.

\section{Acknowledgement}

The authors wish to acknowledge financial support from AWE and the valuable scientific contribution of Geoff Shrimpton (AWE) and Tim Rogers (AWE).

\section{Bibliography}

[1] K. V. Wong, A. Hernandez, A Review of Additive Manufacturing, ISRN Mech. Eng. 2012 (2012) 1-10. doi:10.5402/2012/208760.

[2] E.D. Herderick, Progress in Additive Manufacturing, JOM. 67 (2015) 580-581. doi:10.1007/s11837-015-1323-x.

[3] N. Guo, M.C. Leu, Additive manufacturing: Technology, applications and 
research needs, Front. Mech. Eng. 8 (2013) 215-243. doi:10.1007/s11465-0130248-8.

[4] W.E. Frazier, Metal additive manufacturing: A review, J. Mater. Eng. Perform. 23 (2014) 1917-1928. doi:10.1007/s11665-014-0958-z.

[5] D. Ding, Z. Pan, D. Cuiuri, H. Li, Wire-feed additive manufacturing of metal components: technologies, developments and future interests, Int. J. Adv. Manuf. Technol. 81 (2015) 465-481. doi:10.1007/s00170-015-7077-3.

[6] S.W. Williams, F. Martina, A.C. Addison, J. Ding, G. Pardal, P. Colegrove, Wire + Arc Additive Manufacturing, Mater. Sci. Technol. 32 (2016) 641-647. doi:10.1179/1743284715Y.0000000073.

[7] F. Martina, J. Ding, S. Williams, A. Caballero, G. Pardal, L. Quintino, Tandem metal inert gas process for high productivity wire arc additive manufacturing in stainless steel, Addit. Manuf. 25 (2019) 545-550.

doi:10.1016/j.addma.2018.11.022.

[8] O. Yilmaz, A.A. Ugla, Microstructure characterization of SS308LSi components manufactured by GTAW-based additive manufacturing: shaped metal deposition using pulsed current arc, Int. J. Adv. Manuf. Technol. 89 (2017) 13-25. doi:10.1007/s00170-016-9053-y.

[9] G. Asala, A.K. Khan, J. Andersson, O.A. Ojo, Microstructural Analyses of ATI 718Plus ${ }^{\circledR}$ Produced by Wire-ARC Additive Manufacturing Process, Metall. Mater. Trans. A Phys. Metall. Mater. Sci. 48 (2017) 4211-4228. doi:10.1007/s11661017-4162-2.

[10] F. Wang, S. Williams, P. Colegrove, A. a. Antonysamy, Microstructure and mechanical properties of wire and arc additive manufactured Ti-6Al-4V, Metall. Mater. Trans. A Phys. Metall. Mater. Sci. 44 (2013) 968-977. doi:10.1007/s11661-012-1444-6.

[11] J. Gu, J. Ding, S.W. Williams, H. Gu, P. Ma, Y. Zhai, The strengthening effect of inter-layer cold working and post-deposition heat treatment on the additively manufactured Al-6.3Cu alloy, J. Mater. Process. Technol. 230 (2016) 26-34. doi:10.1016/j.jmatprotec.2015.11.006.

[12] G. Marinelli, F. Martina, S. Ganguly, S. Williams, Development of Wire + Arc additive manufacture for the production of large-scale unalloyed tungsten components, Int. J. Refract. Met. Hard Mater. 82 (2019) 329-335. doi:10.1016/j.jjrmhm.2019.05.009.

[13] G. Marinelli, F. Martina, S. Ganguly, S. Williams, H. Lewtas, D. Hancock, S. Mehraban, N. Lavery, Microstructure and thermal properties of unalloyed tungsten deposited by Wire + Arc Additive Manufacture, J. Nucl. Mater. 522 (2019) 45-53. doi:10.1016/j.jnucmat.2019.04.049.

[14] G. Marinelli, F. Martina, S. Ganguly, S. Williams, Microstructure, hardness and mechanical properties of two different unalloyed tantalum wires deposited via Wire + Arc Additive Manufacture, Int. J. Refract. Met. Hard Mater. 83 (2019) 104974. doi:10.1016/j.ijrmhm.2019.104974. 
[15] G. Marinelli, F. Martina, H. Lewtas, D. Hancock, S. Ganguly, S. Williams, Functionally graded structures of refractory metals by wire arc additive manufacturing, Sci. Technol. Weld. Join. (2019) 1-9. doi:10.1080/13621718.2019.1586162.

[16] H. Lockett, J. Ding, S. Williams, F. Martina, Design for Wire + Arc Additive Manufacture: design rules and build orientation selection, J. Eng. Des. 4828 (2017) 1-31. doi:10.1080/09544828.2017.1365826.

[17] W. Köck, P. Paschen, Tantalum-processing, properties and applications, Jom. 41 (1989) 33-39. doi:10.1007/BF03220360.

[18] M. Bischof, S. Mayer, H. Leitner, H. Clemens, K. Pranzas, P. Staron, G. Dehm, W. Knabl, a. Voiticek, E. Geiger, Microstructure and Mechanical Properties of Si and Y Doped Tantalum, 16th Int. Plansee Semin. (2005) 489-503.

[19] R.W. Buckman, New Applications for Tantalum and Tantalum Alloys, Jom. (2000) 40-41. doi:10.1007/s11837-000-0100-6.

[20] J.. Bechtold, Tensile properties of annealed tantalum at low temperatures, Acta Metall. 3 (1955) 249-254. doi:10.1016/0001-6160(55)90060-2.

[21] S.M. Cardonne, P. Kumar, C.A. Michaluk, H.D. Schwartz, Tantalum and its alloys, Int. J. Refract. Met. Hard Mater. 13 (1995). doi:10.1016/0263-4368(95)94023-R.

[22] L. Zhou, T. Yuan, R. Li, J. Tang, G. Wang, K. Guo, Selective laser melting of pure tantalum: Densification, microstructure and mechanical behaviors, Mater. Sci. Eng. A. 707 (2017) 443-451. doi:10.1016/j.msea.2017.09.083.

[23] L. Thijs, M.L. Montero Sistiaga, R. Wauthle, Q. Xie, J.P. Kruth, J. Van Humbeeck, Strong morphological and crystallographic texture and resulting yield strength anisotropy in selective laser melted tantalum, Acta Mater. 61 (2013) 4657-4668. doi:10.1016/j.actamat.2013.04.036.

[24] V.K. Balla, S. Banerjee, S. Bose, A. Bandyopadhyay, Direct laser processing of a tantalum coating on titanium for bone replacement structures, Acta Biomater. 6 (2010) 2329-2334. doi:10.1016/j.actbio.2009.11.021.

[25] R. Wauthle, J. Van Der Stok, S.A. Yavari, J. Van Humbeeck, J.P. Kruth, A.A. Zadpoor, H. Weinans, M. Mulier, J. Schrooten, Additively manufactured porous tantalum implants, Acta Biomater. 14 (2015) 217-225. doi:10.1016/j.actbio.2014.12.003.

[26] F. Martina, P.A. Colegrove, S.W. Williams, J. Meyer, Microstructure of Interpass Rolled Wire + Arc Additive Manufacturing Ti-6Al-4V Components, Metall. Mater. Trans. A Phys. Metall. Mater. Sci. 46 (2015) 6103-6118. doi:10.1007/s11661015-3172-1.

[27] F. Yan, W. Xiong, E. Faierson, Grain Structure Control of Additively Manufactured Metallic Materials, Materials (Basel). 10 (2017) 1260. doi:10.3390/ma10111260.

[28] H.R.Z. Sandim, J.P. Martins, A.L. Pinto, A.F. Padilha, Recrystallization of oligocrystalline tantalum deformed by cold rolling, Mater. Sci. Eng. A. 392 (2005) 209-221. doi:10.1016/j.msea.2004.09.032. 
[29] A. V. Aditya, P.K. Subramanian, V. Gopala Krishna, U. Chinta Babu, Influence of rolling path on microstructure and mechanical properties in EB refined tantalum, Trans. Indian Inst. Met. 65 (2012) 435-442. doi:10.1007/s12666-0120148-3.

[30] Y. Huang, N. Maury, N.X. Zhang, T.G. Langdon, Microstructures and mechanical properties of pure tantalum processed by high-pressure torsion, Mater. Sci. Eng. 63 (2014) 012100. doi:10.1088/1757-899X/63/1/012100.

[31] O. Renk, P. Ghosh, R. Pippan, Generation of extreme grain aspect ratios in severely deformed tantalum at elevated temperatures, Scr. Mater. 137 (2017) 60-63. doi:10.1016/j.scriptamat.2017.04.024.

[32] S.N. Mathaudhu, K.T. Hartwig, Processing microstructure property relationships in severely deformed tantalum, Mater. Sci. Eng. A. 463 (2007) 94-100. doi:10.1016/j.msea.2006.08.120.

[33] N. Maury, N. Xian, Y. Huang, A.P. Zhilyaev, T.G. Langdon, A critical examination of pure tantalum processed by high-pressure torsion, Mater. Sci. Eng. A. 638 (2015) 174-182. doi:10.1016/j.msea.2015.04.053.

[34] S.L. Lee, M. Doxbeck, J. Mueller, M. Cipollo, P. Cote, Texture, structure and phase transformation in sputter beta tantalum coating, Surf. Coatings Technol. 177-178 (2004) 44-51. doi:10.1016/j.surfcoat.2003.06.008.

[35] E.A.I. Ellis, M. Chmielus, S.P. Baker, Effect of sputter pressure on Ta thin films: Beta phase formation, texture, and stresses, Acta Mater. 150 (2018) 317-326. doi:10.1016/j.actamat.2018.02.050.

[36] S.N. Mathaudhu, K. Ted Hartwig, Grain refinement and recrystallization of heavily worked tantalum, Mater. Sci. Eng. A. 426 (2006) 128-142. doi:10.1016/j.msea.2006.03.089.

[37] K. t. Hartwig, S.N. Mathaudhu, H.J. Maier, I. Karaman, HARDNESS AND MICROSTRUCTURE CHANGES IN SEVERELY DEFORMED AND RECRYSTALLIZED TANTALUM, Ultrafine Grained Mater. II. 11 (2002) 151-160.

[38] G. Marinelli, F. Martina, S. Ganguly, S. Williams, Effect of shielding gas composition and welding speed on autogenous welds of unalloyed tungsten plates, ArXiv.Org. (2019). https://arxiv.org/abs/1902.03904.

[39] F. Martina, J. Mehnen, S.W. Williams, P. Colegrove, F. Wang, Investigation of the benefits of plasma deposition for the additive layer manufacture of Ti-6Al-4V, J. Mater. Process. Technol. 212 (2012) 1377-1386. doi:10.1016/j.jmatprotec.2012.02.002.

[40] Z. Pan, Y. Li, Q. Wei, Tensile properties of nanocrystalline tantalum from molecular dynamics simulations, Acta Mater. 56 (2008) 3470-3480. doi:10.1016/j.actamat.2008.03.025.

[41] H.P. Stüwe, A.F. Padilha, F. Siciliano, Competition between recovery and recrystallization, Mater. Sci. Eng. A. 333 (2002) 361-367. doi:10.1016/S09215093(01)01860-3.

[42] J. Puhr-Westerheide, G. Elssner, On the solid solution hardening of tantalum by 
nitrogen and oxygen, J. Less-Common Met. 20 (1970) 371-374. doi:10.1016/0022-5088(70)90013-5.

[43] S. Stecura, Observation of oxide particles below the apparent oxygen solubility limit in tantalum, Metall. Trans. 5 (1974) 1337-1340. doi:10.1007/BF02646617.

[44] S. Nemat-Nasser, J. B. Isaacs, M. Liu, Microstructure of high-Strain, High-StrainRate Deformed Tantalum, Acta Mater. 46 (1998) 1307-1325.

[45] Y. H. Liu, S. F. Liu, J. L. Zhu, C. Deng, H. Y. Fan, L. F. Cao, Q. Liu, Strain path dependence of microstructure and annealing behavior in high purity tantalum, Mater. Sci. Eng. A. 707 (2017) 518-530. doi:10.1016/j.msea.2017.09.097.

[46] B.J. Duggan, M. Hatherly, W.B. Hutchinson, P.T. Wakefield, Deformation structures and textures in cold-rolled 70:30 brass, Met. Sci. 12 (1978) 343-351.

[47] A.A. Ridha, W.B. Hutchinson, Recrystallisation mechanisms and the origin of cube texture in copper, Acta Metall. 30 (1982) 1929-1939. doi:10.1016/00016160(82)90033-5.

[48] J. Hjelen, R. Orsund, E. Nes, On the Origin of Recrystallization Textures in Aluminum, Acta Met. Mater. 39 (1991) 1377-1404. doi:Doi 10.1016/09567151(91)90225-P. 
2019-12-26

\section{Grain refinement in an unalloyed}

tantalum structure by combining

\section{Wire+Arc additive manufacturing and vertical cold rolling}

Marinelli, Gianrocco

Elsevier

Marinelli G, Martina F, Gangly S, Williams S. (2019) Grain refinement in an unalloyed tantalum structure by combining Wire+Arc additive manufacturing and vertical cold rolling, Additive Manufacturing, Volume 32, March 2019, Article number 101009

https://doi.org/10.1016/j.addma.2019.101009

Downloaded from Cranfield Library Services E-Repository 